\title{
Optic nerve sheath diameter: A novel way to monitor the brain
}

\author{
Seelora Sahu, Amlan Swain
}

\begin{abstract}
Measurement and monitoring of intracranial pressure is pivotal in management of brain injured patients. As a rapid and easily done bed side measurement, ultrasonography of the optic nerve sheath diameter presents itself as a possible replacement of the conventional invasive methods of intracranial pressure management. In this review we go through the evolution of optic nerve sheath diameter measurement as a novel marker of predicting raised intracranial pressure, the modalities by which it can be measured as well as its correlation with the invasive methods of intracranial pressure monitoring.
\end{abstract}

Key words: Intracranial pressure, optic nerve sheath diameter, ultrasonography

\section{INTRODUCTION}

Since the landmark study of Lundberg underlining the significance of intracranial pressure (ICP) monitoring, there have been umpteen studies on the importance of raised ICP and its association with mortality and morbidity in neurologically injured patients. ${ }^{[1]}$ Elevated ICP is a challenging and potentially fatal complication of acute head trauma in patients who present to the emergency department. ${ }^{[2,3]}$ Poor intracranial compliance causes herniation of portions of brain over the dural membranes, ultimately resulting in uncal, central, transtentorial and downward herniation syndromes with catastrophic consequences. ${ }^{[4]}$ There is considerable evidence to indicate ICP as an important independent variable, significantly related to outcome in patients with

Department of Anaesthesia and Critical Care, Tata Main Hospital, Jamshedpur, Jharkhand, India

Address for correspondence:

Dr. Seelora Sahu, A-36, Professional Flats A, B-H Area,

K-S Link Road, Kadma, Jamshedpur - 831 005, Jharkhand, India.

E-mail: seelora@gmail.com

\begin{tabular}{|l|l|}
\hline \multicolumn{2}{|c|}{ Access this article online } \\
\hline Quick Response Code: & Website: \\
\hline & www.jnaccjournal.org \\
\cline { 2 - 2 } & \\
\hline
\end{tabular}

neurological injury. ${ }^{[5]}$ While in some patients intracranial hypertension could be an indicator of overwhelming and irrecoverable brain injury, the argument in favour of actively treating raised ICP is derived primarily from the overwhelming evidence indicating lesser mortality in patients in whom intracranial compliance dysregulation is actively managed. ${ }^{[6]}$

The past 50 years have seen an active and wide-ranging research in the causes and consequences of raised ICP and have simultaneously engaged in such diverse disciplines such as neurosurgery, anaesthesia, radiology, biophysics, electronic and mechanical engineering, mathematics and computer science. This interest has not just been in monitoring pressure alone but also in using information derived from pressure monitoring to help in predicting outcomes and planning the management for brain-injured patients. ${ }^{[7]}$

The Brain Trauma Foundation advocates ICP monitoring in all cases of traumatic brain injury (TBI) with a Glasgow Coma Scale score between 3 and 8 and an abnormal computed tomography (CT) scan

This is an open access article distributed under the terms of the Creative Commons Attribution-NonCommercial-ShareAlike 3.0 License, which allows others to remix, tweak, and build upon the work non-commercially, as long as the author is credited and the new creations are licensed under the identical terms.

For reprints contact: reprints@medknow.com

How to cite this article: Sahu S, Swain A. Optic nerve sheath diameter: A novel way to monitor the brain. J Neuroanaesthesiol Crit Care 2017;4:S13-8. 
(scan showing haematomas, contusion, swelling, herniation or compressed basal cisterns) ${ }^{[8,9]}$ Patient outcome was poor when ICP exceeded $22 \mathrm{mmHg}$ while an improved outcome was reported when ICP was maintained below $15 \mathrm{mmHg} .{ }^{[10,11]}$ Saul and Ducker were amongst the first to suggest that early and aggressive treatment of modest rise of ICP has the potential of avoiding its deleterious sequelae. ${ }^{[11]}$ Contant $e t$ al. found that critical values independently related to poor outcome were ICP $>25 \mathrm{mmHg}$, mean blood pressure $(\mathrm{BP})<80 \mathrm{mmHg}$ and cerebral perfusion pressure $<60 \mathrm{mmHg} \cdot{ }^{[12]}$

\section{DISCUSSION}

\section{Measurement of intracranial pressure}

The advent of routine direct monitoring of ICP began in 1960 and is credited to Lundberg, who described the method of directly monitoring the fluid pressure in the ventricle. ${ }^{[1]}$ The next milestone in ICP monitoring came in 1973 with the introduction of the subarachnoid screw (bolt), which led to the development of other methods of monitoring ICP, including the subdural cup catheter, extradural monitors and the fibre-optic catheter. Since then, owing to the development of catheter-tip pressure transducers, parenchymal monitoring has also evolved. Each type of device, depending on the intracranial location and method of pressure transduction, has its advantages and disadvantages. ${ }^{[13]}$ The methods of measuring ICP can be classified as either invasive or non-invasive.

Invasive methods to monitor ICP include devices such as an intraventricular catheter, extraventricular drain, intraparenchymal probes and subarachnoid bolts. ${ }^{[7,14]}$ The intraventricular monitoring of ICP is considered as gold standard for ICP measurement. ${ }^{[15]}$ While invasive methods of ICP monitoring give the advantage of precise and accurate measurements, placement of intra ventricular drain is associated with numerous complications such as difficult placement, haemorrhage, infections, incorrect placement as well as those related to sudden decompression. ${ }^{[16-18]}$

The idea of a non-invasive method of measuring ICP is captivating, as complications seen in relation to the invasive methods of ICP measurement such as haemorrhage and infection are then avoidable. ${ }^{[19]}$ The non-invasive methods of monitoring ICP which have evolved over time include modalities such as optic nerve sheath diameter (ONSD) measurements, tympanic membrane displacement, transcranial Doppler ultrasonography (USG), transcranial ultrasound propagation, measurements of the dielectric property of the cranium, magnetic resonance imaging (MRI) and magnetic resonance angiography, computerised tomography scans, quantitative pupillometry and opthalmodynamometry. ${ }^{[19]}$

\section{Optic nerve sheath diameter}

The fact that the optic nerve sheath is an extension of the dura mater enclosing the optic nerve up to the back of the eye was established as early as 1780 by Zinn and Wrisberg in their 'Descriptio anatomica oculi humani'. ${ }^{[20]}$ However, it was only at the fag end of the previous century when it became established that changes in the ONSD reflect alterations in the ICP. This startling discovery was attributed to be a consequence of subarachnoid fluid inside the optic nerve sheath being in direct continuation with the subarachnoid fluid of the intracranial compartment. The optic nerve, as the part of central nervous system, is covered by a leptomeningeal sheath, which is expandable in the anterior segment, behind the globe [Figure 1]. When ICP rises, cerebrospinal fluid (CSF) is pushed towards the tiny rim of subarachnoid space between the sheath and the nerve, causing an expansion of the dural covering. These changes are more marked in the anterior part of the nerve sheath behind the globe. ${ }^{[21]}$ As with any physiological change, the ONSD changes dynamically with changes in ICP. ${ }^{[21]}$

It was Hayreh who demonstrated the presence of a constant communication between the subarachnoid space of the optic nerve sheath and the intracranial cavity while studying rhesus monkeys in $1968 .{ }^{[2]} \mathrm{He}$ also showed the utility of ultrasound in documenting the phenomenon of alterations in the diameter of the optic nerve sheath with consequent changes in intracranial CSF pressure. Two decades later, Hansen and Helmke conducted a prospective interventional study by placing spinal needle at two levels in patients presenting for regular scheduled lumbar puncture to remove CSF. ${ }^{[23]}$

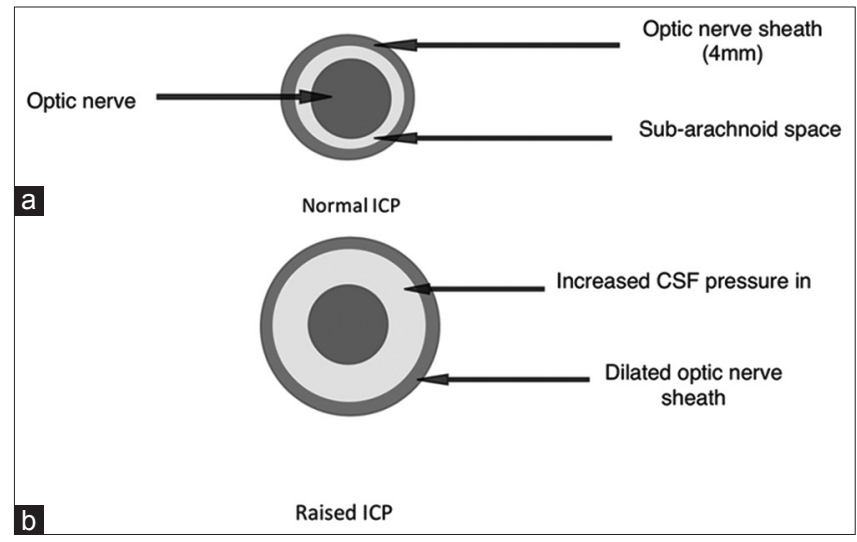

Figure 1: A cross-section of the optic nerve. The subarachnoid space separates the optic nerve from the optic nerve sheath (a) the normal state. (b) After dilatation of the optic nerve sheath as a consequence of increased cerebrospinal fluid pressure in the subarachnoid space. CSF: Cerebrospinal fluid, ICP: Intracranial pressure 
By removing and infusing liquid into the subarachnoid space, measuring CSF pressure changes and performing ultrasound examinations of the optic nerve sheath, they were able to demonstrate a direct relationship between increasing ICP and dilation of the optic nerve sheath. The effect seemed to plateau at an ONSD of just over $7 \mathrm{~mm}$. This phenomenon was reversed when ICP was lowered by removing excess CSF. They also went on to specify the exact depth at which to measure the ONSD for it to be the most accurate reflection of changes in the ICP and established that the ONSD experienced wider changes at a depth of $3 \mathrm{~mm}$ front the globe as compared to any other part of the optic nerve. ${ }^{[23]}$

\section{Optic nerve sheath diameter measurements}

The ONSD can be measured by CT, MRI and USG [Figures 2 and 3].

\section{Optic nerve sheath diameter by computer tomography}

The diagnostic accuracy, reproducibility of ONSD measurement by CT scan and its correlation with ICP have been demonstrated in many studies in patients with normal as well as raised ICP. ${ }^{[24,25]}$ A recent study on 300 patients revealed the normal ONSD to be $4.94 \pm 1.51 \mathrm{~mm}$ on the right side and $5.17 \pm 1.34 \mathrm{~mm}$ on the left side, at $3 \mathrm{~mm}$ depth from the eye globe. ${ }^{[26]}$

Sekhon et al. found ONSD to correlate well with invasive ICP in severe TBI cohort with a low interobserver variability. ${ }^{[27]}$ Using $6 \mathrm{~mm}$ cut-off, the area under curve was 0.83 (95\% confidence interval [CI]: 0.73-0.94), with positive predictive value of $67 \%$ and negative predictive value of $92 \%$. They concluded that ONSD measurement by $\mathrm{CT}$ was a much stronger predictor

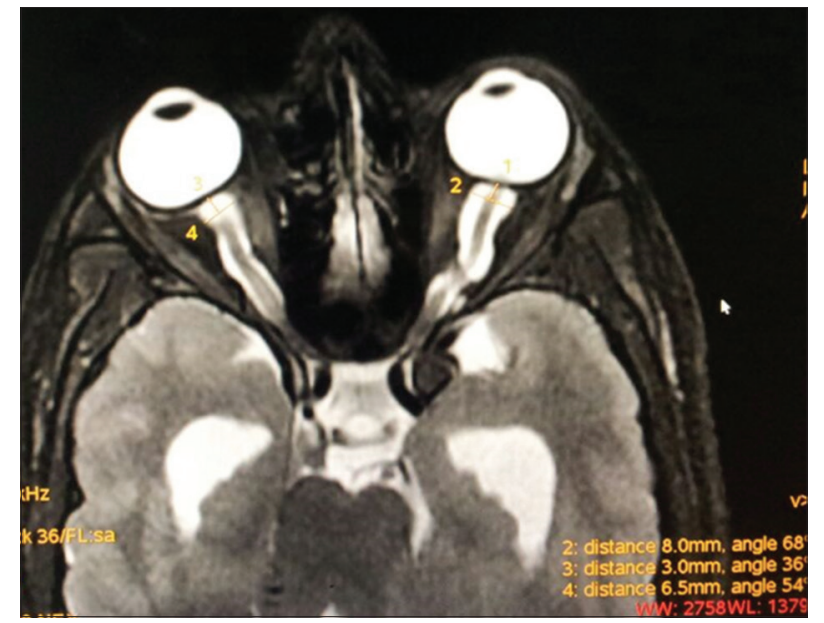

Figure 2: Axial films of magnetic resonance imaging images showing optic nerve sheath diameter measurements. The figure shows the measurement by electronic calipers in millimetres. 1 and 3 measure the distance from the eyeball at which the optic nerve sheath diameter measurement is taken. 2 and 4 measure the optic nerve sheath diameter at a depth of $3 \mathrm{~mm}$ from the eye ball of ICP (R2 of 0.56) compared to other CT features (R2 of 0.21$)^{[25]}$ The same group consequently found that risk of in-hospital mortality doubled with each $1 \mathrm{~mm}$ increase in ONSD (odds ratio: 2.0, 95\% CI: 1.2-3.2, $P=0.007) \cdot{ }^{[27]}$

\section{Optic nerve sheath diameter by magnetic resonance imaging}

The ONSD dimensions measured by MRI have been reliable in predicting ICP as reported by recent studies. Geeraerts et al. found that ONSD measured by conventional brain T2-weighted MRI correlates with invasive ICP. ${ }^{[28]}$ They have demonstrated that an enlarged ONSD was a robust predictor of raised ICP with an area under Receiver Operating Statistic (ROC) curve equal to 0.94 . An ONSD $<5.30 \mathrm{~mm}$ was unlikely to be associated with raised ICP, whereas an ONSD above $5.82 \mathrm{~mm}$ was associated with a $90 \%$ probability of raised ICP. ${ }^{[28]}$

\section{Ultrasonography of the optic nerve sheath}

Optic nerve sheath ultrasound is a simple, safe, inexpensive, bedside diagnostic test analogous to the measurement of BP and has the potential to replace invasive ICP monitoring in cases of raised intracranial hypertension. Ophthalmic ultrasound typically uses a frequency between 5 and $10.5 \mathrm{MHz}$ to evaluate the eye and orbit. ${ }^{[29]}$

Helmke and Hansen used ultrasound in cadavers to prove that in the area just behind the eyeball, elevated pressure can increase the sheath diameter by $>50 \%$. ${ }^{[30]}$ In another study, the same authors used intrathecal infusion tests to prove that the ONSD varies with alteration of lumbar CSF pressure. ${ }^{[31]}$ A similar study was done by Tamburrelli et al., who showed that the

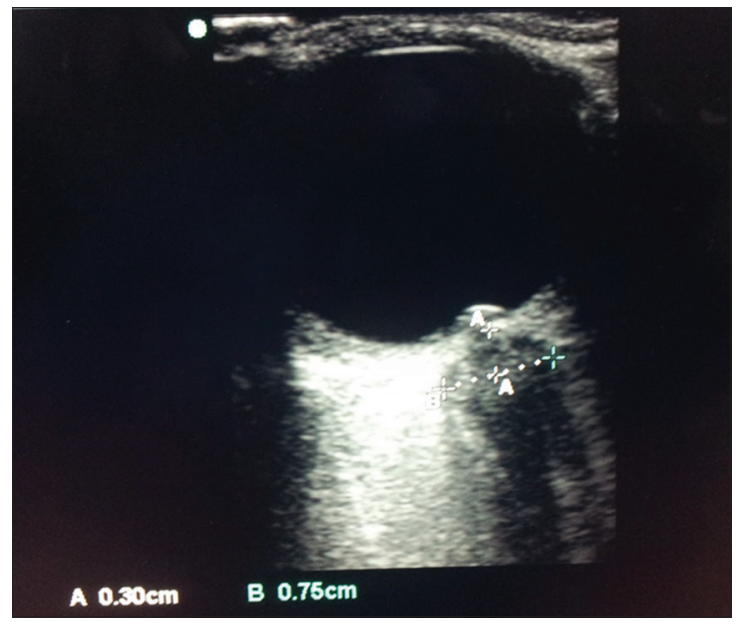

Figure 3: Ultrasonography image of optic nerve sheath diameter measurement. The figure shows the ultrasound measurement of optic nerve sheath diameter in centimetres. The caliper ' $A$ ' measures the depth (from the eyeball) at which the optic nerve sheath diameter has to be measured $(3 \mathrm{~mm})$. ' $\mathrm{B}$ ' measures the optic nerve sheath diameter $(7.5 \mathrm{~mm})$ at this depth 
optic nerve sheath begins to expand when the diastolic ICP is increased to $>13-14 \mathrm{mmHg} .{ }^{[32]}$ Beyond that point, a linear correlation is seen between the enlargement of the optic nerve sheath and simultaneous increases in ICP. These changes in the optic nerve sheath occur before changes in the nerve are visible on fundoscopic examination. Using $4.5 \mathrm{~mm}$ as the cut-off for normal, Tamburrelli et al. found a sensitivity of echocardiography to identify an ICP $>15 \mathrm{mmHg}$ of $88 \%$ and a specificity of 90\%. ${ }^{[32]}$ Previous studies have demonstrated that ONSD can be used as a non-invasive indicator of raised ICP. ${ }^{[33]}$

Tayal et al. conducted a prospective, double-blind study in 55 patients and found that an ONSD of $5.0 \mathrm{~mm}$ or more correlated with CT findings suggestive of raised ICP ${ }^{[34]}$ Cranial CT findings of shift, oedema or effacement suggestive of elevated ICP were used to evaluate ONSD accuracy. In the recent clinical studies, ONSD has been correlated with clinical symptoms and $\mathrm{CT}$ abnormalities, both surrogate indicators of elevated ICP. ${ }^{[13]}$ In a recent study correlating ONSD with CT features of raised ICP, Aduayi et al. demonstrated a good reliability of optic nerve sheath ultrasound in predicting raised ICP. ${ }^{[35]}$ A recent systematic review and meta-analysis has confirmed that ocular ultrasound exhibits good diagnostic test accuracy for detecting raised ICP compared to $\mathrm{CT}$, specifically high sensitivity, for ruling out raised ICP in a low-risk group and high specificity for ruling out raised ICP in a high-risk group. ${ }^{[36]}$

ONSD measured by ultrasound has also been correlated with ONSD by MRI. Bäuerle et al. established the reproducibility and accuracy of ONSD measurement using MRI and USG $(r=0.72, P=0.002$, mean difference $<5 \%){ }^{[37]}$ They carried out two scans each for the sonographic and MRI measurements of ONSD and established that sonographic ONSD quantification $3 \mathrm{~mm}$ behind the papilla can be performed with good reproducibility, measurement accuracy and observer agreement. They have emphasised that this technique can be used as a non-invasive bedside tool for longitudinal ONSD measurements. ${ }^{[37]}$ More recently, Shirodkar et al. have correlated sonographic ONSD with the ONSD measured by MRI to confer to the same conclusion that they correlate well. ${ }^{[38]}$

There have been few studies which directly correlated ONSD measurements on ultrasound with ICP measured invasively. The cut-off value for normal ONSD, measured $3 \mathrm{~mm}$ posterior to the globe, ranges from 5.2 to $5.9 \mathrm{~mm}$. Ultrasound of the optic nerve sheath has also been compared to the findings of increased ICP on CT, such as changes in ventricle size, basilar cistern size, sulci size, degree of transfalcine herniation and grey/white matter differentiation. An ONSD value of $5.0 \mathrm{~mm}$ as cut-off, measured by CT scan, indicated ICP $>20 \mathrm{mmHg}$ as shown by a study conducted by Qayyum et al. who also showed that the ultrasound-guided ONSD is a sensitive and specific test for predicting elevated ICP. ${ }^{[39]}$ Some authors have shown that with a cut-off of normal ONSD ranging from 5.0 to $5.9 \mathrm{~mm} \cdot{ }^{[15]}$ Kimberly et al. suggested an ONSD cut-off of $5.0 \mathrm{~mm}$ for predicting an ICP $>20 \mathrm{mmHg}{ }^{[40]}$ In a recent study conducted by Amini et al., an ONSD of $5.5 \mathrm{~mm}$ predicted an ICP $>20 \mathrm{mmHg}$ with a sensitivity of $100 \%$ and specificity of $100 \%$. ${ }^{[41]}$ Similarly, Sahoo and Deepak Agrawal have reported a cut-off of $6.3 \mathrm{~mm}$ for predicting a ICP $>20 \mathrm{mmHg}$ in patients of neurocritical care by using Codman intraparenchymal probes $(n=20) \cdot{ }^{[42]}$ There are a few studies where the authors have directly correlated ONSD measurements by ultrasound with ICP measured invasively. Invasive pressure has been measured from an external ventricular drain already placed inside the ventricles for routine monitoring, intraparenchymal probes, subarachnoid bolts and intraparenchymal catheters. The cut-off value for ONSD, measured $3 \mathrm{~mm}$ posterior to the globe, correlating with elevated ICP (ICP > $20 \mathrm{mmHg}$ ) ranges from 4.8 to $6.0 \mathrm{~mm} .{ }^{[43]}$

Although majority of work in the realm of ONSD has been achieved in the subsets of neurocritical care (TBI, subarachnoid haemorrhage, hydrocephalus, etc.), fresh evidence of its utility has been explored in disease states such as idiopathic intracranial hypertension (IIH), acute mountain sickness (AMS), tubercular meningitis and eclampsia/preeclampsia. A study comparing the efficacy of MRI versus B scan USG-derived ONSD in IIH patients showed MRI to be better in measuring ONSD as a surrogate of ICP and diagnosing dysfunctional intracranial compliance. ${ }^{[4]}$ In patients with confirmed tuberculous meningitis also, ONSD values have been proven to be more than in the general population and hence afford a cost-effective non-invasive method for monitoring response to treatment. ${ }^{[45]}$ Efficacy of ONSD in the diagnosis of AMS has also been investigated, but the results have been mixed at best, and there is a need to conduct further well-directed research in this topic. ${ }^{[46]}$ ONSD has emerged as a promising tool in the assessment, risk stratification and diagnosis of incipient intracranial hypertension in pregnant patients with pre-eclampsia/eclampsia. ${ }^{[47,48]}$ Sonographic assessment of ONSD has also presented itself as a useful method in the diagnosis of increased ICP in the emergency department even in patients with no history of trauma. ${ }^{[49]}$

Dubourg et al. did a systematic review and meta-analysis and concluded that USG of ONSD shows a good level of diagnostic accuracy for detecting intracranial hypertension. They emphasised on the enormous potential this diagnostic method has in clinical decision-making, whether it be the triage of patients requiring transfer to specialised centres or the need to place an invasive device in situations where there is a lack of specific recommendations for their placement. ${ }^{[50]}$ 
Even though the major limitation in the routine use of ONSD measurements in clinical practice was the lack of specificity, the high sensitivity it offered as a rapid predictor for changes in ICP has made it a good diagnostic tool for not only tailoring the management of patients but also in prognostication in both the emergency department as well as in the critical care setup. ${ }^{[51,52]}$

Several studies have examined variables affecting the accuracy of ultrasound in measuring ONSD. Ultrasound is subject to artefacts, and measuring the ONSD in off-axis may result in an erroneous value. Romagnuolo et al. showed that the ONSD does not change with patient position. ${ }^{[53]}$ Interobserver variation is quite low, and the measurements are highly reproducible, even for novice operators taught in a single training session. ${ }^{[54]}$

While the use of CT and MRI for ONSD is limited by the fact that these two measurements require transfer of the patient to the radiology suite, which might not be welcome in a critical care setup, the use of ultrasound to measure the ONSD has its own limitations. There are concerns related to the heating of the probe causing damage to the internal structures of the eye although no such event has been reported so far. This, however, makes it prudent to limit the duration of procedure to as low as possible. It is also very important to place the probe as lightly as possible on the eyelids so as to prevent any injury due to excessive pressure and avoid the procedure altogether in cases where the patient has ophthalmologic condition such as glaucoma or trauma to the eye. ${ }^{[55]}$

\section{CONCLUSION}

ONSD has presented itself as an exciting option for the measurement of intracranial compliance in brain-injured states and offers the advantages of being a simple, non-invasive and readily available diagnostic modality. However, issues persist with its correlation with the gold standard invasive ICP measurement, and future research will hopefully establish ONSD by USG as a useful bedside tool in clinical decision-making in neuroanaesthesiology and neuro-critical care setups.

\section{Financial support and sponsorship}

Nil.

\section{Conflicts of interest}

There are no conflicts of interest.

\section{REFERENCES}

1. Lundberg N. Continuous recording and control of ventricular fluid pressure in neurosurgical practice. Acta Psychiatr Scand Suppl 1960;36:1-193.

2. American College of Surgeons. Head Trauma. Chicago, IL: American College of Surgeons; 1997. p. 181-206.

3. Brain Injury Foundation, American Association of Neurological
Surgeons, Joint Section on Neurotrauma and Critical Care. Initial management. J Neurotrauma 2000;17:463-9.

4. Gjerris F, Brennum J. The cerebrospinal fluid, intracranial pressure and herniation of the brain. In: Paulson OB, Gjerris F, Sørensen PS, editors. Clinical Neurology and Neurosurgery. Copenhagen: FADL's Forlag Aktieselskab; 2004. p. 179-96.

5. Marmarou A, Anderson RL, Ward JD, Choi SC, Young HF, Eisenberg HM, et al. Impact of ICP stability and hypotension on outcome in patients with severe head trauma. J Neurosurg 1991;66:883-90.

6. Eisenberg HM, Frankowski RF, Contant CF, Marshall LF, Walker MD. High-dose barbiturate control of elevated intracranial pressure in patients with severe head injury. J Neurosurg 1988;69:15-23.

7. Steiner LA, Andrews PJ. Monitoring the injured brain: ICP and CBF. Br J Anaesth 2006;97:26-38.

8. Brain Trauma Foundation; American Association of Neurological Surgeons; Congress of Neurological Surgeons; Joint Section on Neurotrauma and Critical Care, AANS/CNS, Bratton SL, Chestnut RM, Ghajar J, McConnell Hammond FF, et al. Guidelines for the management of severe traumatic brain injury. VI. Indications for intracranial pressure monitoring. J Neurotrauma 2007;24 Suppl 1:S37-44.

9. Carney N, Totten AM, O $\square$ Reilly C, Ullman JS, Hawryluk GW, Bell MJ, et al. Guidelines for the Management of Severe Traumatic Brain Injury, Fourth Edition. Neurosurgery 2016. [Epub ahead of print].

10. Miller JD, Butterworth JF, Gudeman SK, Faulkner JE, Choi SC, Selhorst JB, et al. Further experience in the management of severe head injury. J Neurosurg 1981;54:289-99.

11. Saul TG, Ducker TB. Effect of intracranial pressure monitoring and aggressive treatment on mortality in severe head injury. J Neurosurg 1982;56:498-503.

12. Contant CF, Robertson CS, Gopinath SP, Narayan RK, Grossman RG. Determination of clinically important thresholds in continuously monitored patients with head injury. J Neurotrauma 1993;10(Suppl 1):S102.

13. Zhong J, Dujovny M, Park HK, Perez E, Perlin AR, Diaz FG. Advances in ICP monitoring techniques. Neurol Res 2003;25:339-50.

14. The Brain Trauma Foundation. The American Association of Neurological Surgeons. The Joint Section on Neurotrauma and Critical Care. Indications for intracranial pressure monitoring. J Neurotrauma 2000;17:479-91.

15. Rosenberg JB, Shiloh AL, Savel RH, Eisen LA. Non-invasive methods of estimating intracranial pressure. Neurocrit Care 2011;15:599-608.

16. Binz DD, Toussaint LG $3^{\text {rd }}$, Friedman JA. Hemorrhagic complications of ventriculostomy placement: A meta-analysis. Neurocrit Care 2009;10:253-6.

17. Lozier AP, Sciacca RR, Romagnoli MF, Connolly ES Jr. Ventriculostomy-related infections: A critical review of the literature. Neurosurgery 2001;51:170-81.

18. Saladino A, White JB, Wijdicks EF, Lanzino G. Malplacement of ventricular catheters by neurosurgeons: A single institution experience. Neurocrit Care 2009;10:248-52.

19. Raboel PH, Bartek J Jr., Andresen M, Bellander BM, Romner B. Intracranial pressure monitoring: Invasive versus non-invasive methods - A review. Crit Care Res Pract 2012;2012:950393.

20. Zinn IG. Nervus oculi. Descriptio Anatomica Oculi Humani Iconibus Illustrata. $1^{\text {st }}$ ed., Ch. 9. Gottingae: Vidum Abrami Vandenhoeck B; 1755. p. 183-9.

21. Helmke K, Hansen HC. Fundamentals of transorbital sonographic evaluation of optic nerve sheath expansion under intracranial hypertension II. Patient study. Pediatr Radiol 1996;26:706-10.

22. Hayreh SS. Pathogenesis of oedema of the optic disc. Doc Ophthalmol 1968;24:289-411. 
23. Hansen HC, Helmke K. Validation of the optic nerve sheath response to changing cerebrospinal fluid pressure: Ultrasound findings during intrathecal infusion tests. J Neurosurg 1997;87:34-40.

24. Zaidi SJ, Yamamoto LG. Optic nerve sheath diameter measurements by CT scan in ventriculoperitoneal shunt obstruction. Hawaii J Med Public Health 2014;73:251-5.

25. Sekhon MS, Griesdale DE, Robba C, McGlashan N, Needham E, Walland $\mathrm{K}$, et al. Optic nerve sheath diameter on computed tomography is correlated with simultaneously measured intracranial pressure in patients with severe traumatic brain injury. Intensive Care Med 2014;40:1267-74.

26. Vaiman M, Abuita R, Bekerman I. Optic nerve sheath diameters in healthy adults measured by computer tomography. Int J Ophthalmol 2015;8:1240-4.

27. Sekhon MS, McBeth P, Zou J, Qiao L, Kolmodin L, Henderson WR, et al. Association between optic nerve sheath diameter and mortality in patients with severe traumatic brain injury. Neurocrit Care 2014;21:245-52.

28. Geeraerts T, Newcombe VF, Coles JP, Abate MG, Perkes IE, Hutchinson PJ, et al. Use of T2-weighted magnetic resonance imaging of the optic nerve sheath to detect raised intracranial pressure. Crit Care 2008;12:R114.

29. Shah S, Kimberly H, Marill K, Noble VE. Ultrasound techniques to measure the optic nerve sheath: Is a specialized probe necessary? Med Sci Monit 2009;15:MT63-8.

30. Helmke K, Hansen HC. Fundamentals of transorbital sonographic evaluation of optic nerve sheath expansion under intracranial hypertension. I. Experimental study. Pediatr Radiol 1996;26:701-5.

31. Hansen HC, Helmke K. The subarachnoid space surrounding the optic nerves. An ultrasound study of the optic nerve sheath. Surg Radiol Anat 1996;18:323-8.

32. Tamburrelli C, Anile C, Mangiola A, Falsini B, Palma P. CSF dynamic parameters and changes of optic nerve diameters measured by standardized echography. In: Till P, editor. Ophthalmic Echography 13: Proceedings of the $13^{\text {th }}$ SIDUO Congress, Vienna, Austria, 1990. Netherlands: Kluwer Academic Publishers; 1993. p. 101-9.

33. Blaivas M, Theodoro D, Sierzenski PR. Elevated intracranial pressure detected by bedside emergency ultrasonography of the optic nerve sheath. Acad Emerg Med 2003;10:376-81.

34. Tayal VS, Neulander M, Norton HJ, Foster T, Saunders T, Blaivas M. Emergency department sonographic measurement of optic nerve sheath diameter to detect findings of increased intracranial pressure in adult head injury patients. Ann Emerg Med 2007;49:508-14.

35. Aduayi OS, Asaleye CM, Adetiloye VA, Komolafe EO, Aduayi VA. Optic nerve sonography: A noninvasive means of detecting raised intracranial pressure in a resource-limited setting. J Neurosci Rural Pract 2015;6:563-7.

36. Ohle R, Mclsaac SM, Woo MY, Perry JJ. Sonography of the optic nerve sheath diameter for detection of raised intracranial pressure compared to computed tomography: A systematic review and meta-analysis. J Ultrasound Med 2015;34:1285-94.

37. Bäuerle J, Schuchardt F, Schroeder L, Egger K, Weigel M, Harloff A. Reproducibility and accuracy of optic nerve sheath diameter assessment using ultrasound compared to magnetic resonance imaging. BMC Neurol 2013;13:187.

38. Shirodkar CG, Munta K, Rao SM, Mahesh MU. Correlation of measurement of optic nerve sheath diameter using ultrasound with magnetic resonance imaging. Indian J Crit Care Med 2015;19:466-70.

39. Qayyum H, Ramlakhan S. Can ocular ultrasound predict intracranial hypertension? A pilot diagnostic accuracy evaluation in a UK emergency department. Eur J Emerg Med 2013;20:91-7.
40. Kimberly HH, Shah S, Marill K, Noble V. Correlation of optic nerve sheath diameter with direct measurement of intracranial pressure. Acad Emerg Med 2008;15:201-4.

41. Amini A, Kariman H, Arhami Dolatabadi A, Hatamabadi HR, Derakhshanfar H, Mansouri B, et al. Use of the sonographic diameter of optic nerve sheath to estimate intracranial pressure. Am J Emerg Med 2013;31:236-9.

42. Sahoo SS, Deepak Agrawal D. Correlation of optic nerve sheath diameter with intracranial pressure monitoring in patients with severe traumatic brain injury. Indian J Neurotrauma 2013;10:9-12.

43. Kristiansson $\mathrm{H}$, Nissborg E, Bartek J Jr., Andresen M, Reinstrup $\mathrm{P}$, Romner $\mathrm{B}$. Measuring elevated intracranial pressure through noninvasive methods: A review of the literature. J Neurosurg Anesthesiol 2013;25:372-85.

44. Kilji M, Srinivasan A, Bhanu K, Samivel B, Ranganathan L. Comparison of the Measurement of Optic Nerve Sheath Diameter (ONSD) with B Scan and MRI as a Surrogate for Patients with Idiopathic Intracranial Hypertension (IIH)(P6. 316). Neurology 2016;86(16 Supplement):6-316.

45. Sangani SV, Parikh S. Can sonographic measurement of optic nerve sheath diameter be used to detect raised intracranial pressure in patients with tuberculous meningitis? A prospective observational study. Indian J Radiol Imaging 2015;25:173-6.

46. LochnerP,Falla M,BrigoF,Pohl M,Strapazzon G.Ultrasonography of the optic nerve sheath diameter for diagnosis and monitoring of acute mountain sickness: A systematic review. High altitude medicine \& Biology 2015;16(3):195-203.

47. Ferro F, Rocha E, Nobrega L, Amorim MM, Katz L. Transorbital Ultrasonographic Measurement of the Optic Nerve Sheath Diameter in Preeclampsia [24J]. Obstetrics \& Gynecology 2016;127:87S.

48. Ortega J, Urias EG, Arteaga C. Comparative study measuring optic nerve sheath diameter by transorbital ultrasound in healthy women, pregnant women and pregnant with preeclampsia/eclampsia. Intensive Care Medicine Experimental 2015;3:1.

49. Komut E, Kozaci N, Sönmez BM, Yilmaz F, Komut S, Yildirim ZN, et al. Bedside sonographic measurement of optic nerve sheath diameter as a predictor of intracranial pressure in ED. Am J Emerg Med 2016;34:963-7.

50. Dubourg J, Javouhey E, Geeraerts T, Messerer M, Kassai B. Ultrasonography of optic nerve sheath diameter for detection of raised intracranial pressure: A systematic review and meta-analysis. Intensive Care Med 2011;37:1059-68.

51. Legrand A, Jeanjean P, Delanghe F, Peltier J, Lecat B, Dupont $\mathrm{H}$. Estimation of optic nerve sheath diameter on an initial brain computed tomography scan can contribute prognostic information in traumatic brain injury patients. Crit Care 2013;17:R61.

52. Shirodkar CG, Rao SM, Mutkule DP, Harde YR, Venkategowda PM, Mahesh MU. Optic nerve sheath diameter as a marker for evaluation and prognostication of intracranial pressure in Indian patients: An observational study. Indian J Crit Care Med 2014;18:728-34.

53. Romagnuolo L, Tayal V, Tomaszewski C, Saunders T, Norton HJ. Optic nerve sheath diameter does not change with patient position. Am J Emerg Med 2005;23:686-8.

54. Du Toit GJ, Hurter D, Nel M. How accurate is ultrasound of the optic nerve sheath diameter performed by inexperienced operators to exclude raised intracranial pressure? S Afr J Radiol 2015;19:5.

55. Barnett SB, Ter Haar GR, Ziskin MC, Rott HD, Duck FA, Maeda K. International recommendations and guidelines for the safe use of diagnostic ultrasound in medicine. Ultrasound Med Biol 2000;26:355-66. 